\title{
Influence of age and artificial vaginal stimulation on fertility in female bank voles (Clethrionomys glareolus)
}

\author{
Lilian M. Westlin* and T. O. Gustafsson† \\ Department of Zoology, University of Lund, S-223 62 Lund, Sweden
}

\begin{abstract}
Summary. Female bank voles mated when $30-50$ days old showed only $20-25 \%$ fertility at the first mating, but fertility increased to about $80 \%$ in animals $>100$ days of age at the first mating. Young females subjected to artificial cervical stimulation after the completion of a normal mating showed a much higher fertility than normally mated controls ( 76 compared with $29 \%$ ). The reason for the low fertility therefore appears to be that young females require more stimulation to activate the corpora lutea than is normally received at a mating.
\end{abstract}

\section{Introduction}

At the start of the breeding season, many microtine rodents ovulate several times in rapid succession before their first pregnancy. This is also seen in the young of that year before their first pregnancy (Brambell \& Rowlands, 1936; Brambell \& Hall, 1939; Hoyte, 1955; Greenwald, 1956; Coutts \& Rowlands, 1969; Kirkpatrick \& Valentine, 1970; Mallory \& Clulow, 1977; Westlin, 1982a; Westlin \& Nyholm, 1982). These sterile ovulations result in several sets of corpora lutea with little activity (Brambell \& Rowlands, 1936; Coutts \& Rowlands, 1969; Westlin \& Nyholm, 1982). Historically, this was taken as evidence for spontaneous ovulations (Brambell \& Rowlands, 1936; Brambell \& Hall, 1939), but since then it has been shown that most, if not all, microtines are reflex ovulators (Breed, 1967; Clarke, Clulow \& Greig, 1970; Milligan, 1975a; Westlin \& Nyholm, 1982).

'Sterile ovulations' have further been regarded as evidence for the occurrence of pregnancy block (Bruce, 1959) in natural populations (Clarke \& Clulow, 1973; Clulow \& Mallory, 1974; Mallory \& Clulow, 1977). Another possible explanation would involve the mechanism for activation of the corpus luteum in these species. Microtines have a multiple intromission-multiple ejaculation copulatory pattern (Dewsbury, 1973; Gray \& Dewsbury, 1973, 1975; Milligan, 1975b, 1979; Kenney, Hartung \& Dewsbury, 1979). In many species, e.g. Microtus agrestis, $M$. montanus and Clethrionomys glareolus, ovulation is triggered by the first few intromissions, whereas a longer period of vaginal stimulation is needed to activate development of the corpora lutea (Milligan, 1975a; Kenney \& Dewsbury, 1977; Andersson \& Gustafsson, 1982).

Young female bank voles frequently fail to become pregnant at their first matings. This occurs if the stud male is left with the female (Westlin \& Nyholm, 1982) as well as if the stud male is removed and the female kept alone (Westlin, 1982b). Young females may have higher requirements for vaginal stimulation to activate the luteotrophic complex and one explanation for their lower fertility could be that the stimulus threshold for activation is seldom reached. We have investigated the luteotrophic effect of artificial vaginal stimulation after complete mating in young female bank voles and the relation between fertility and age.

* Present address: AB LEO, Research Laboratories of Pharmacology Department, Fack, S-251 09 Helsingborg, Sweden.

† Present address: Zoologisk Institutt, University of Oslo, Blindern, Oslo 3, Norway. 


\section{Materials and Methods}

Animals. Female bank voles (Clethrionomys glareolus) from a laboratory colony kept at the Department of Zoology, University of Lund, Sweden (Gustafsson, Andersson \& Westlin, 1980) were used. They were housed in standard plastic cages with wire mesh lids and with wood shavings as litter. They were fed a commercial mouse food supplemented once a week with guinea-pig food. The photoperiod was $18 \mathrm{~h}$ light $: 6 \mathrm{~h}$ dark. The females were kept in groups of 5 from weaning at Day 18 after birth until the start of mating tests.

Treatments. In Exp. 1, the fertility at the first mating in females, 30-180 days old, was recorded. At the beginning of the mating tests, females were put singly in new cages. An adult male was introduced in the morning, and the female was checked for a vaginal plug or mating behaviour every $3 \mathrm{~h}$. If mating had occurred, the male was left with the female for $24 \mathrm{~h}$, and was then removed. If no mating had occurred at 17:00 $\mathrm{h}$ the male was removed and a new one was introduced the following day. Females which had not mated after 10 tests were discarded.

In Exp. 2, females were kept in groups as above until 30 days old, when they were subjected to mating tests as above. After mating, the male was left with the female overnight and then removed. At $4 \mathrm{~h}$ after mating was detected, half of the females were subjected to additional artificial vaginal stimulation with a vibrating plastic rod. The rod was placed in the vagina for $2 \mathrm{sec}$ at 15 -sec intervals during a 2 -min period. Five such 2 -min stimulation periods were given at 10 -min intervals. The stimulation regimen was based on observations of the mating behaviour of bank voles (Dewsbury, 1973; Gray \& Dewsbury, 1973, 1975; Milligan, 1975b, 1979; Kenney et al., 1979). The remaining females were left undisturbed. The females were kept singly until autopsy 6 days after mating. At autopsy the incidence of pregnancy was recorded. At this time, the embryos are visible as 3-4 mm swellings (Andersson \& Gustafsson, 1979). The number and macroscopic appearance of corpora lutea were noted. The ovaries were dissected out, fixed in Bouin's fluid, and routinely embedded in paraffin wax. They were serially sectioned at $7 \mu \mathrm{m}$, stained with a tetrachrome combination according to Borg, Andersson \& Meurling (1978) and studied by light microscopy.

\section{Results}

\section{Experiment 1}

The fertility at the first mating was strongly influenced by age. Fertility increased from less than $25 \%$ in females younger than 50 days to $\sim 80 \%$ in females $120-180$ days old (Text-fig. 1 ).

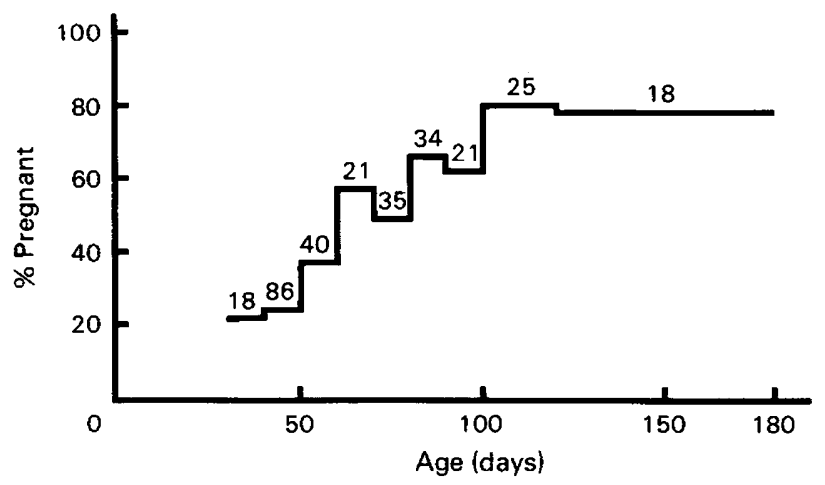

Text-fig. 1. Fertility in relation to age in primigravid female bank voles. For each age interval, the no. of females is shown. 


\section{Experiment 2}

Artificial vaginal stimulation after the first mating increased fertility from 29 to $76 \%$ (Table 1 ). The pregnant animals had large, active corpora lutea, whereas the non-pregnant voles had small, poorly vascularized CL (Westlin \& Nyholm, 1982; Westlin, 1982b).

Table 1. Fertility of young female bank voles after complete mating or complete mating followed by additional vaginal stimulation with a vibrating plastic rod

\begin{tabular}{lcccc}
\hline & \multicolumn{4}{c}{ No. of females } \\
\cline { 2 - 5 } & Studied & Ovulated & Pregnant & $\begin{array}{c}\text { With active } \\
\text { CL }\end{array}$ \\
\hline $\begin{array}{l}\text { Normal mating } \\
\text { Normal mating }+ \\
\text { mechanical stimulation }\end{array}$ & 17 & 17 & 5 & 5 \\
\hline
\end{tabular}

$P<0.025$ compared with normally mated females (G-test of independence).

\section{Discussion}

The present results show that the infertility in young female bank voles is caused by the fact that the stimulus threshold for activation of the corpora lutea is only seldom reached at normal matings. We do not know whether this is because young females do not allow the males to mate until satiety, or because the threshold is higher than the satiety point for males, although a limited study on sexual behaviour in young and old females suggests that the latter explanation is true (L. M. Westlin \& T. O. Gustafsson, unpublished).

Since fertility increases with age (Text-fig.), it seems that the stimulation threshold is lowered with age. Increasing age is not the only lowering factor, however. If females are allowed to mate when young with vasectomized males, the fertility at their second mating is much higher than that of similarly aged primigravid females (Westlin \& Gustafsson, 1983). It therefore seems that young female bank voles reach the first oestrus before they are likely to become pregnant, and use the first matings to lower the stimulus threshold.

In nature, infertility is seen in young females reaching puberty during their first summer and in older females during the reinitiation of breeding activity in spring. The corpora lutea formed after infertile matings in these two categories of females are histologically very similar (Westlin \& Nyholm, 1982). We believe that the infertility has similar causes in both cases. The present paper suggests that the cause is immaturity of the mechanism activating the luteotrophic complex, rather than pregnancy block. The similarity between different microtine species in the occurrence of sterile ovulations in natural populations (Westlin, 1982a; Westlin \& Nyholm, 1982) as well as in the mechanism for activation of the luteotrophic complex (Milligan, 1982) may be taken as an indication of a similar explanation for their infertility.

This work was supported by the Swedish Natural Science Research Council and the Royal Physiographic Society, Lund.

\section{References}

Andersson, C.B. \& Gustafsson, T.O. (1979) Delayed implantation in lactating bank voles, Clethrionomys glareolus. J. Reprod. Fert. 57, 349-352.

Andersson, C.B. \& Gustafsson, T.O. (1982) Effect of limited and complete mating on ovaries and adrenals in bank voles, Clethrionomys glareolus. J. Reprod. Fert. 64, 431-435.
Borg, B., Andersson, M. \& Meurling, P. (1978) The biology of the wild rabbit, Oryctolagus cuniculus, in southern Sweden. III. Histology of the uterus in the non-breeding season. Acta zool., Stockh. 59, 253-260.

Brambell, F.W.R. \& Hall, K. (1939) Reproduction in the field vole, Microtus agrestis hirtus Bellamy. Proc. zool. Soc. Lond. 109, 133-138. 
Brambell, F.W.R. \& Rowlands, I.W. (1936) Reproduction of the bank vole (Evotomys glareolus, Schreber). I. The oestrus cycle of the female. Phil. Trans. R. Soc. Lond. B 216, 71-97.

Breed, W.G. (1967) Ovulation in the genus Microtus. Nature, Lond. 214, 826.

Bruce, H.M. (1959) An exteroceptive block of pregnancy in the mouse. Nature, Lond. 184, 105.

Clarke, J.R. \& Clulow, F.V. (1973) The effect of successive matings upon bank vole (Clethrionomys glareolus) and vole (Microtus agrestis) ovaries. In The Development and Maturation of the Ovary and its Functions, pp. 160-170. Ed. H. Peters. Excerpta Medica (ICS No. 267), Amsterdam.

Clarke, J.R., Clulow, F.V. \& Greig, F. (1970) Ovulation in the bank vole, Clethrionomys glareolus. J. Reprod. Fert. 25, 531, Abstr.

Clulow, F.V. \& Mallory, F.F. (1974) Ovaries of meadow voles, Microtus pennsylvanicus, after copulation with a series of males. Can. J. Zool. 52, 265-267.

Coutts, R.R. \& Rowlands, I.W. (1969) The reproductive cycle of the skomer vole, Clethrionomys glareolus skomeriensis. J. Zool., Lond. 158, 1-26.

Dewsbury, D.A. (1973) Copulatory behavior of montane voles (Microtus montanus). Behaviour 44, 186-202.

Gray, G.D. \& Dewsbury, D.A. (1973) A quantitative description of copulatory behaviour in prairie voles (Microtus ochrogaster). Brain Behav. Evol. 8, 437-452.

Gray, G.D. \& Dewsbury, D.A. (1975) A quantitative description of the copulatory behaviour of meadow voles (Microtus pennsylvanicus). Anim. Behav. 23, 261-267.

Greenwald, G.S. (1956) The reproductive cycle of the field mouse (Microtus californicus). J. Mammal. 37, 213-222.

Gustafsson, T.O., Andersson, C.B. \& Westlin, L.M. (1980) Reproduction in a laboratory colony of bank voles, Clethrionomys glareolus. Can. J. Zool. 58, 10161021.

Hoyte, H.M.D. (1955) Observations on reproduction in some small mammals of arctic Norway. J. Anim. Ecol. 24, 412-425.
Kenney, A. McM. \& Dewsbury, D.A. (1977) Effect of limited mating on the corpora lutea in montane voles, Microtus montanus. J. Reprod. Fert. 49, 363-364.

Kenney, A. McM., Hartung, T.G. \& Dewsbury, D.A. (1979) Copulatory behaviour and the initiation of pregnancy in California voles (Microtus californicus). Brain Behav. Evol. 16, 176-191.

Kirkpatrick, R.L. \& Valentine, G.L. (1970) Reproduction in captive pine voles, Microtus pinetorum. J. Mammal. 51, 779-785.

Mallory, F.F. \& Clulow, F.V. (1977) Evidence of pregnancy failure in the wild meadow vole, Microtus pennsylvanicus. Can. J. Zool. 55, 1-17.

Milligan, S.R. (1975a) Mating, ovulation and corpus luteum function in the vole, Microtus agrestis. $J$. Reprod. Fert. 42, 35-44.

Milligan, S.R. (1975b) The copulatory behaviour of Microtus agrestis. J. Mammal. 56, 220-224.

Milligan, S.R. (1979) The copulatory pattern of the bank vole (Clethrionomys glareolus) and speculation on the role of penile spines. $J$. Zool, , Lond. 188, 279-282.

Milligan, S.R. (1982) Induced ovulation in mammals. Oxford Rev. Reprod. Biol. 4, 1-46.

Westlin, L.M. (1982a) Sterile matings at the beginning of the breeding season in Clethrionomys rufocanus and Microtus agrestis. Can. J. Zool. 60, 2568-2571.

Westlin, L.M. (1982b) Increased fertility in young primiparous female bank voles, Clethrionomys glareolus, treated with prolactin or progesterone after mating. J. Reprod. Fert. 66, 113-115.

Westlin, L.M. \& Gustafsson, T.O. (1983) Influence of sexual experience and social environment on fertility and incidence of mating in young female bank voles (Clethrionomys glareolus). J. Reprod. Fert. 69, 173177.

Westlin, L.M. \& Nyholm, E. (1982) Sterile matings initiate the breeding season in the bank vole, Clethrionomys glareolus. A field and laboratory study. Can. J. Zool. 60, 387-391.

Received 8 August 1983 